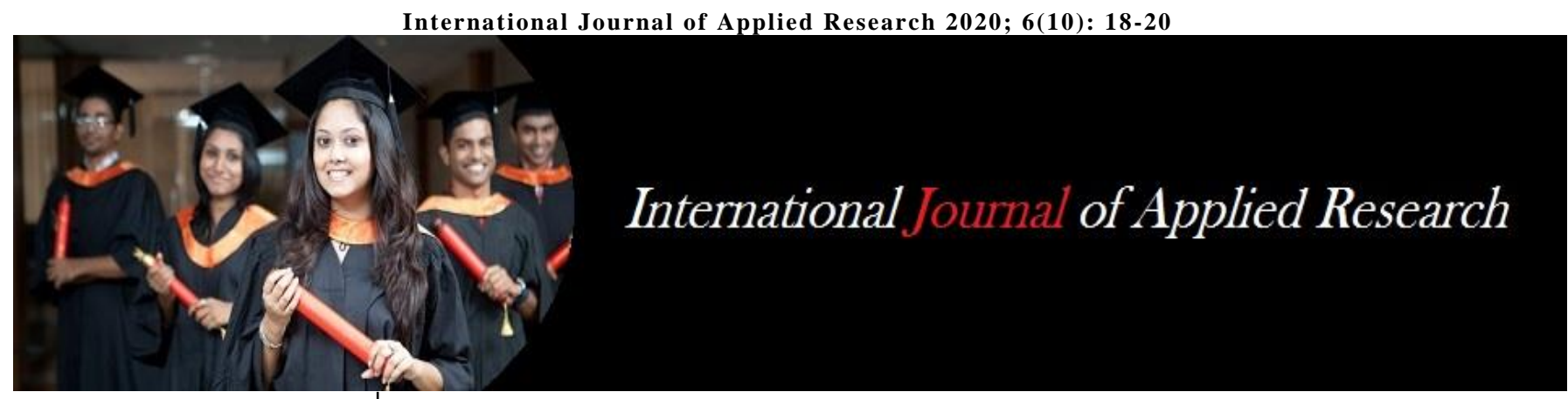

ISSN Print: 2394-7500

ISSN Online: 2394-5869

Impact Factor: 5.2

IJAR 2020; 6(10): 18-20

www.allresearchjournal.com

Received: 13-08-2020

Accepted: 15-09-2020

Nidhi Kumari

Guest Faculty, Department of

Commerce Bhagalpur National

College Tilka Manjhi

Bhagalpur University

Bhagalpur, Bihar, India
Corresponding Author:

Nidhi Kumari

Guest Faculty, Department of

Commerce Bhagalpur National

College Tilka Manjhi

Bhagalpur University

Bhagalpur, Bihar, India

\section{India's contribution to science}

\section{Nidhi Kumari}

DOI: https://doi.org/10.22271/allresearch.2020.v6.i10a.7206

\section{Abstract}

Indian citizens have transformed the way the world works, India is a land where numerous brilliant brains have made contribution in the field of science and enhanced its position around the globe. India has the second largest group of scientists in the world. one of the oldest civilizations in the world, the Indian civilization has a strong tradition of science. Ancient India was a land of sages and seers as well as a land of scholars and scientists. India was actively contributing to the field of science centuries long before modern laboratories were set up. Many theories and techniques discovered by the ancient Indians have created and strengthened the fundamentals of modern science. While some of these groundbreaking contributions have been acknowledged, some are still unknown to most. India's contribution in the field of science draws from the whole cultural and technological history of India, during which architecture, astronomy, cartography, metallurgy, logic, mathematics, metrology and mineralogy . A systematic approach is made in this article to capture and express India's contribution in the field of science starting from pre independent era to post independent. On the basis of secondary data collected from the periodicals, journal articles, and reports etc present study attempts to portray the scenario of India's contribution in the field of science.

Keywords: Scientist, India, extraordinary contribution

\section{Introduction}

Indian citizens have transformed the way the world works, India is a land where numerous brilliant brains have made contribution in the field of science and enhanced its position around the globe. India has the second largest group of scientists in the world. One of the oldest civilizations in the world, the Indian civilization has a strong tradition of science. Ancient India was a land of sages and seers as well as a land of scholars and scientists.

Science can be described as systematic analysis of any question. Science is in no way limited to the laboratories or classrooms. What our mother does as part of her cooking process in her kitchen, skills that have been owned over years of experimentation and careful observation, is not far from a scientist experimenting in a lab. The person who invented the wheel, the person who discovered fire, the tribe that discovered agriculture, they were all scientists in their own right.

India was actively contributing to the field of science centuries long before modern laboratories were set up. Many theories and techniques discovered by the ancient Indians have created and strengthened the fundamentals of modern science. While some of these groundbreaking contributions have been acknowledged, some are still unknown to most. India's contribution in the field of science draws from the whole cultural and technological history of India, during which architecture, astronomy, cartography, metallurgy, logic, mathematics, metrology and mineralogy.

\section{Objective of the study}

This study has conducted to review the scholarly article and different reports to draw a systematic structure about the India's contribution in the field of science. Objective of the study is

- To do a systematic review of India's contribution in the field of Science.

- To highlight India's contribution in the different area's of science. 
As India's contribution is uncountable in this field but here author try to limelight on some extraordinary contribution in the different area of science.

\section{Methodology of the study}

A systematic approach was made in this article to capture and draw a systematic structure about India's contribution in the field of Science on the basis of secondary sources. Data were collected from the periodicals, journal articles, news articles governmental and non- governmental reports such as different privately funded research institutions report.

\section{Findings of the study}

After doing the systematic review of secondary sources such as journal articles, news articles, and reports some extraordinary contribution could be lined up as follows (as India's contribution is not restricted up to this) :

\section{India's contribution in the field of medical science}

Yoga: Modern-day science confirms that the practice of yoga has tangible physical health benefits that include improved brain function and denser bones, as well as immune health, improved nervous system functioning and strength.

India is the origin of yoga. It is developed by the Indus Sarasvati civilization in northern India over 5000year ago. In the field of yoga the concept of international Yoga day was first proposed by the current Prime Minister of India, Narendra Modi, during his speech at the United Nations General Assembly (UNGA), on 27 September 2014 so that people on the globe get aware about its benefit and make their life easy and healthy and result is that over millions of people in all over the world enjoy the benefits of a stronger body, calm mind, increased happiness and reduced stress. yoga is supreme science it is known as heritage of India and in this regard UNESCO also listed yoga as an intangible cultural heritage.

Ayurveda: Ayurveda is India's invaluable contribution to the field of Medicine. Father of Indian Medicine, Charaka laid the foundation of modern day Ayurveda. He was the first physician to present and elaborate the concepts of digestion, metabolism and immunity system. He talks about three element which the body contains i.e. Vata (movement), Pitta (transformation) and Cough (lubrication and stability). this is a very big contribution in this field because a human suffers from the different diseases when the balance among these three elements get disturbed.

Plastic surgery \& Cataract Surgery: The concept of surgery given by Sushruta who was an Indian Physician. In the field of medical science, it's gave a revolutionary change and for his remarkable contribution, today he known as the father of Surgery and Father of Plastic Surgery.

\section{India's contribution in the field of Spatial Science}

In this field there are lots of contribution but some of them are extraordinary contribution in itself like as:

Mangalyaan-1: The mars Orbiter Mission made India the only nation in the world to reach Mars in its first attempt.

Chandrayaan 2: Is an Indian lunar mission that will boldly go where no country has ever gone before the Moon's south polar region. Through this effort, the aim is to improve our understanding of the Moon discoveries that will benefit India and humanity as a whole. These insights and experiences aim at a paradigm shift in how lunar expeditions are approached for years to come propelling further voyages into the farthest frontiers.

Indian Regional Navigation Satellite System (IRNSS) is an independent satellite navigation system. It has freed India from its dependence on navigation satellite systems operated by other countries. It serves as home grown GPS system as a strategic asset of Indian military for it's tremendous significance.

Indian National Satellite System (INSAT) is a series of multipurpose Geo-stationary satellites is one of the largest domestic communication satellite system owned by any country in the Asia-Pacific region. It initiated a major revolution in India's communications sector. At present, it is serving several crucial sectors of our economy, including telecommunication, education, and meteorology.

India's contribution in the field of mathematical science: Zero: Zero is the one of the most important invention in India. Mathematician Aryabhata was the First person to create a symbol for zero and it was through his efforts that mathematical operations like addition and subtraction started using the digit, zero.

Decimal System: India gave the ingenious method of expressing all numbers by means of ten symbols - the decimal system. In this system, each symbol received a value of position as well as an absolute value and it facilitated calculation.

Fibonacci Numbers \& Binary Number: The Fibonacci numbers and their sequence first appear in Indian mathematics and Binary numbers is the basic language in which computer programs are written. Binary basically refers to a set of two numbers, 1 and 0 , the combinations of which are called bits and bytes. The concept of Fibonacci and binary firstly given by Indian Mathematician Acharya Pingala.

\section{Contribution in the field of metallurgy}

Seamless Metal Globe: Considered one of the most remarkable feats in metallurgy, the first seamless celestial globe was made in Kashmir by Ali Kashmiri ibn Luqman in the reign of the Emperor Akbar.

Smelting of Zinc: India was the First to smelt zinc by the distillation process, an advanced technique derived from a long experience of ancient alchemy. It is an important contribution of India to the world of science.

Iron Cased Rocket were another contribution in the field of metallurgy science it were developed by Tipu Sultan in the year 1780s.

\section{India's contribution in the field of Architecture}

India have a huge unbelievable contribution in the field of architecture.

Iron Pillars in Delhi is itself the example of India's extraordinary work in this field even after a long time this pillar remain as same as before.

Drainage system of Harappan civilization is another example of the architectural science. The most striking 
feature of this Harappan civilization (Indus Valley Civilization) is that the Indus Valley people had constructed their drainage system on very scientific lines. The drainage system of Mohen-jo-daro is so elaborate that "the like of which has not yet been found anywhere in the world in any other city of the same antiquity."

India's contribution in the field of environmental science Green concept of sustainable development: Sunita Narain is an Indian environmentalist proponent of the Green concept of sustainable development. Here sustainable development itself mean that economic development that is conducted without depletion of natural resources and from this concept of sustainable development make us aware how to use our valuable resources and make our development smoothly without any cost.

International solar alliance: International solar alliance is a remarkable contribution in this field. This alliance is initiated by India on $30^{\text {th }}$ Nov. 2015 with the objective to reduce cost of power using natural resources and, in this way, also contribute for enhancement of the Indian economy.

\section{Conclusion}

After doing systematic study of India's contribution from pre independent era to post independent era using different secondary sources it can be said that all contribution is extraordinary and our Indians is really brilliant minded. There contribution is not rewarded in the field of science only but each and every aspect of our life and in this way it can be said Indian have done phenomenal work.

\section{References}

1. Bharati V. Indian Contribution to Science. New Delhi: Vigyan Bharti, 2017.

2. India: Science and Technology. (n.d.). Retrieved August 15, 2019, from Topper Classes: https://www.toppr.com/guides/general-

knowledge/india-science-and-technology/sciencetechnology-in-india/

3. Insights IAS. Achievements of Indian Scientists in 2018. Achievements of Indians in science \& technology; indigenization of technology and developing new technology, 2018,

4. ISA Prospective Member Countries. (2016, November 15). Retrieved August 17, 2019, from IAS International Solar Alliance: http://isolaralliance.org/MemberCont.aspx

5. Katariya M. 15 Indian Achievements That Helped Push Technological Boundaries The World Over. 15 Indian Achievements That Helped Push Technological Boundaries The World Over, 2018.

6. Pal S. 16 Significant Science and Tech Discoveries Ancient India Gave the World. 2016. Retrieved August 16, 2019, from The Better India: https://www.thebetterindia.com/63119/ancient-indiascience-technology/

7. Today G. Achievements of Indians in Science \& Technology: Contemporary, 2017. 